\title{
Intraoperative electrophysiology during single-level selective dorsal rhizotomy: technique, stimulation threshold, and response data in a series of 145 patients
}

\author{
*Philippe De Vloo, MD, PhD, ${ }^{1,2}$ Terhi J. Huttunen, MD, PhD, ${ }^{1}$ Dalila Forte, MD, ${ }^{1}$ Ivana Jankovic, BSc, ${ }^{3}$ \\ Amy Lee, BSc, ${ }^{3}$ Mark Hair, BSc, ${ }^{3}$ Stephanie Cawker, BSc, ${ }^{4}$ Deepti Chugh, MSc, ${ }^{4}$ Lucinda Carr, MD, ${ }^{4}$ \\ Belinda H. A. Crowe, MD, ${ }^{4}$ Matthew Pitt, MD, ${ }^{3}$ and Kristian Aquilina, MD ${ }^{1}$
}

Departments of ${ }^{1}$ Neurosurgery, ${ }^{3}$ Neurophysiology, and ${ }^{4}$ Neurodisability, Great Ormond Street Hospital for Children, London, United Kingdom; and 2Department of Neurosurgery, University Hospitals Leuven, Belgium

\begin{abstract}
OBJECTIVE Selective dorsal rhizotomy (SDR) is effective at permanently reducing spasticity in children with spastic cerebral palsy. The value of intraoperative neurophysiological monitoring in this procedure remains controversial, and its robustness has been questioned. This study describes the authors' institutional electrophysiological technique (based on the technique of Park et al.), intraoperative findings, robustness, value to the procedure, and occurrence of new motor or sphincter deficits.
\end{abstract}

METHODS The authors analyzed electrophysiological data of all children who underwent SDR at their center between September 2013 and February 2019. All patients underwent bilateral SDR through a single-level laminotomy at the conus and with transection of about $60 \%$ of the L2-S2 afferent rootlets (guided by intraoperative electrophysiology) and about $50 \%$ of $L 1$ afferent roots (nonselectively).

RESULTS One hundred forty-five patients underwent SDR (64\% male, mean age 6 years and 7 months, range 2 years and 9 months to 14 years and 10 months). Dorsal roots were distinguished from ventral roots anatomically and electrophysiologically, by assessing responses on free-running electromyography (EMG) and determining stimulation thresholds ( $\geq 0.2 \mathrm{~mA}$ in all dorsal rootlets). Root level was determined anatomically and electrophysiologically by assessing electromyographic response to stimulation. Median stimulation threshold was lower in sacral compared to lumbar roots $(p<0.001)$, and $16 \%$ higher on the first operated (right) side $(p=0.023)$, but unrelated to age, sex, or functional status. Similarly, responses to tetanic stimulation were consistent: $87 \%$ were graded $3+$ or $4+$, with similar distributions between sides. This was also unrelated to age, sex, and functional status. The L2-S2 rootlets were divided (median $60 \%$, range $50 \%-67 \%$ ), guided by response to tetanic stimulation at threshold amplitude. No new motor or sphincter deficits were observed, suggesting sparing of ventral roots and sphincteric innervation, respectively.

CONCLUSIONS This electrophysiological technique appears robust and reproducible, allowing reliable identification of afferent nerve roots, definition of root levels, and guidance for rootlet division. Only a direct comparative study will establish whether intraoperative electrophysiology during SDR minimizes risk of new motor or sphincter worsening and/ or maximizes functional outcome.

https://thejns.org/doi/abs/10.3171/2019.12.PEDS19372

KEYWORDS selective dorsal rhizotomy; intraoperative electrophysiology; cerebral palsy; spasticity; functional neurosurgery

$\mathrm{S}$ ELECTIVE dorsal rhizotomy (SDR) is an established surgical treatment for spasticity in carefully selected patients with spastic cerebral palsy $(\mathrm{CP}) .{ }^{2}$ Several trials have shown long-term benefit following SDR in combination with physiotherapy versus physiotherapy alone, ${ }^{18,19}$, 37,45 a more sustained response of SDR versus botulinum toxin injections, ${ }^{44}$ and a reduced requirement for botulinum toxin injections and orthopedic interventions after SDR compared with matched control patients. ${ }^{4,14,21,44} \mathrm{Re}$ cently, we have shown in a multicenter study that SDR in ambulatory children with moderate $\mathrm{CP}$ improves functionality (vs expected natural history) and quality of life

ABBREVIATIONS Cl = confidence interval; $\mathrm{CP}=$ cerebral palsy; EMG = electromyography; GMFCS = Gross Motor Function Classification System; SDR = selective dorsal rhizotomy.

SUBMITTED June 25, 2019. ACCEPTED December 30, 2019.

INCLUDE WHEN CITING Published online February 28, 2020; DOI: 10.3171/2019.12.PEDS19372.

* P.D.V. and T.J.H. contributed equally to this study and share first authorship. 
(vs preoperatively). ${ }^{40}$ The underlying rationale for this procedure is that, in patients with $\mathrm{CP}$, the input entering the spinal cord through the posterior roots has a net excitatory effect on the anterior roots, and that spasticity can be reduced by transecting these roots, without causing permanent sensory or motor deficits. ${ }^{13,41}$

Dorsal rhizotomy was first reported by Abbe in 1888 (himself crediting Dana), for relief of "violent neuralgic pains." ${ }^{.1}$ Reports of reduced comorbid spasticity in patients after this procedure, and observations of absence of spasticity in patients with hemiplegic tabes dorsalis, eventually led to the first dorsal rhizotomy for spasticity in 1908 by Foerster, who completely sectioned the posterior roots of L2-S2, sparing L4 or L5 to preserve knee extensor tone. ${ }^{2,8,26}$ Due to high morbidity and mortality, this technique was largely abandoned until the 1960s and 1970s, when several refinements were proposed to increase the selectivity. First, the Montpellier group of Gros reported selective transection of rootlets innervating muscles displaying "handicapping" spasticity, sparing those displaying "useful" spasticity (i.e., functionally useful for gait). Their decision was based on a combination of preoperative clinical assessment and intraoperative clinical and electrophysiological response to continuous electrical stimulation with fixed parameters. ${ }^{12,29}$

In 1978, Fasano and coworkers, from Turin, proposed that selectivity should be entirely based on electrophysiological response to intraoperative electrical stimulation, rather than on clinical assessment. Abnormal responses were defined as: 1) an abnormal threshold to a train of stimuli; 2) spread to muscles that were not primarily innervated by the stimulated root; and 3) crossover activation. ${ }^{6,7}$ Of note, Foerster, Gros, and Fasano all used a surgical approach limited to the conus/cauda interface. In an attempt to reduce the high incidence of bladder and bowel dysfunction by unambiguous sacral root identification, Peacock's Cape Town group proposed a more extensive L2-5 laminectomy, and always spared S2, regardless of its electrophysiological response. ${ }^{3,26}$ Although it remains unproven that this more extensive approach increases the incidence of spinal deformities compared to the natural history of $\mathrm{CP}, 11,33$ or that a more limited approach or laminoplasty causes less spinal deformity than a multilevel approach, ${ }^{10,30}$ the group of Park et al., from St. Louis, again minimized the approach and used intraoperative ultrasonography to optimally position the single-level laminectomy over the conus. Also different from the method of Peacock is that Park and colleagues selectively transected S2 rootlets to improve ankle spasticity, ${ }^{15}$ with only minimal risk of bladder and bowel dysfunction. ${ }^{24,25}$

While many authors regard the aid of electrophysiology for SDR procedures as indispensable, $, 3,6,7,25,26$ and the majority of groups apply it, ${ }^{34}$ both the validity of the electrophysiological criteria to select which rootlets to cut, and the overall value of electrophysiology in obtaining a good functional outcome with a low complication rate, have been questioned. . $^{13,16,17,28,32,34,38}$ Indeed, there are currently no universally accepted surgical techniques or neurophysiology protocols. ${ }^{41}$ The main technical differences between different groups encompass: 1) the surgical approach (single-level vs multilevel, laminotomy vs lam- inoplasty); 2) the degree of root splitting (ranging from 3 to $>20$ rootlets); 3 ) the relative importance of electrophysiological versus clinical responses in the decision to transect; and 4) the neurophysiological technique. Variations in neurophysiological technique include differences in setup (surface vs depth electrodes), coverage (whether or not to record from the upper limbs), relative position of anodal and cathodal stimulator, stimulation parameters, and definition of stimulation threshold and normal and abnormal responses. ${ }^{34}$

This study describes the intraoperative neurophysiological monitoring protocol and findings from a series of 145 patients who underwent SDR via a Park technique single-level approach. The aim of this work is three-fold: 1) describe our electrophysiological technique and electrophysiological findings in detail, which may be useful for any group wishing to set up an SDR program, and for groups already performing SDR procedures with intraoperative electrophysiology to allow benchmarking of their findings; 2) illustrate that the stimulation threshold and stimulation responses were robust, both within patients (when comparing thresholds and responses on both sides, with significant manipulations in between) and between patients (of different ages, sexes, and functional status) and can be elicited and interpreted using a standard scale irrespective of age, sex, and functional status differences; and 3) assess whether our patients suffered new motor or sphincter deficits after SDR with intraoperative electrophysiological monitoring as described.

\section{Methods}

\section{Study Participants and Data Collection}

We collected demographic, functional, and electrophysiological data from our institutional SDR database, and included all patients who underwent SDR between September 1, 2013, and February 15, 2019, at Great Ormond Street Hospital in London, United Kingdom. Preoperative overall functional status was measured using the Gross Motor Function Classification System (GMFCS). ${ }^{23}$ Our patient selection criteria for SDR have been published elsewhere. ${ }^{2}$ As per institutional policy, this retrospective analysis of anonymized data did not require formal IRB approval.

\section{Surgical Technique}

Our surgical technique is similar to that described by Park and Johnston. ${ }^{25}$ In brief, the patient is anesthetized using sevoflurane and remifentanil, avoiding muscle relaxants and propofol,,$^{31}$ and positioned prone with the abdomen maximally decompressed, with the head slightly lower than the spine. Next, the location of the conus/cauda interface is determined using transcutaneous ultrasound (in younger children), or using a combination of the preoperative MR image and palpation or fluoroscopy (in older children, typically at T12-L1). An approximately $4-\mathrm{cm}$ incision is made, and a T12-L1 fenestration is performed to create an acoustic window. A transdural ultrasound scan now determines whether a craniotome-assisted laminotomy is performed in the cranial or caudal direction, to create a bone window directly above the conus. The dura 
is then opened longitudinally under the operating microscope. We always start on the right side and slightly tilt the operating table away from that side to maximize the view. After opening the arachnoid, the dorsal roots are identified anatomically and electrophysiologically, and isolated from the ventral roots with a cottonoid and a silastic sheet. The L2 root can be seen approaching its lateral recess and foramen, and the more caudal lumbosacral roots follow in lateromedial order.

Using rhizotomy stimulation hooks (Peacock probes, Aesculap), the L2-S2 roots are arbitrarily divided into a number of rootlets of similar thickness. This number is dependent on the relative thickness of the individual roots. Typically, on either side, L2 and L3 roots are divided in 3 rootlets each, L4 in 4, L5 and S1 in 5 each, and S2 in 2-3 each. Next, these rootlets are electrically stimulated, and then cut or preserved based on their electrophysiological response. Most commonly, we transect two of three L2 and L3 rootlets, two or three of four L4 rootlets, and three of five L5 and S1 rootlets. Before 2016, S2 roots were not usually transected, and more recently, typically about half of the rootlets are cut, but only after excluding an important contribution to anal sphincteric innervation. The purpose of S2 transection is maximal reduction of plantar flexion spasticity. Finally, approximately half of the L1 afferent root, as visualized in its foramen, is severed in a nonselective manner. Of note, there was no intraoperative clinical assessment of stimulation responses. The same steps are then repeated on the left side, followed by watertight dural closure, replacement of the removed lamina with sutures or plates, and wound closure.

\section{Electrophysiological Setup}

Needle electrodes (Neuroline twisted pair subdermal, Ambu) are inserted bilaterally in the adductor longus (mainly innervated via L2-3), vastus lateralis (L3-4), tibialis anterior (L4-5), peroneus longus (L5), gastrocnemius (S1), abductor hallucis (S2), and sphincter ani (S2-4). We also insert an electrode in the brachioradialis bilaterally. These 16 channels are connected to an electrophysiology workstation (Xltek Protektor) and the entire setup is tested before draping.

For direct intraoperative stimulation, we suspend the rootlets with 2 rhizotomy hooks, with the cathode proximally and anode distally (allowing orthodromic stimulation), held approximately $1 \mathrm{~cm}$ apart.

\section{Intraoperative Electrophysiology}

To identify the ventral or dorsal nature of the root, electrophysiology can be used in addition to anatomical verification. For this purpose, both free-running electromyography (EMG) and low-amplitude stimulation are applied. A clear EMG response is expected when gently tapping the ventral roots, whereas no EMG response is observed upon gentle manipulation of the dorsal roots. Stimulation of the ventral roots with a $0.05-0.1-\mathrm{mA}$ square pulse wave typically elicits a brisk EMG and clinical response, while a substantially higher amplitude is usually required to obtain a similar response to stimulation of the dorsal roots.

To electrophysiologically identify the level of a dorsal root, the root is lifted up with both rhizotomy hooks and stimulated (0.2-msec square-wave pulses at $3 \mathrm{~Hz}$ with increasing amplitude). Given the significant overlap in the muscle innervation, we rely on the muscle displaying the largest EMG response, combined with anatomical information.

Following identification, the root is divided into a number of rootlets using the rhizotomy hooks or a sharp hook. The individual rootlets are then suspended over the rhizotomy hooks and stimulated (0.2-msec square-wave pulses at $3 \mathrm{~Hz}$ ) with an amplitude increasing in a stepwise fashion from 0.1 to $20 \mathrm{~mA}$ until an EMG reflex response with a peak-to-peak amplitude exceeding $200 \mu \mathrm{V}$ is observed from its main related muscle. This stimulation amplitude is called the stimulation threshold. Next, a $50-\mathrm{Hz}$ train of tetanic stimulation with identical pulses at threshold amplitude is applied for 1 second. The obtained electrophysiological response is graded on a 0 to $4+$ scale according to the Phillips and Park SDR reflex grading criteria (Table 1, Fig. 1). "3,20,25,27,43 This grading system allows distinction between "normal" (grade 0 to $2+$ ) and "abnormal" (grade $3+$ to $4+$ ) responses.

\section{Transection of Rootlets}

Overall, we aim to cut $60 \%-67 \%$ of rootlets, as proposed by Park, ${ }^{25}$ and for each root, at least 1 rootlet is spared. Candidate rootlets for transection need to show an abnormal (grade 3+ to 4+) stimulation response with no or minimal anal sphincter involvement. In case all rootlets of a particular root display abnormal responses, the ones with the most abnormal response are cut, or when there is no detectable difference between responses of the different rootlets, an arbitrary decision is made. Rootlets displaying a normal (grade 0 to $2+$ ) stimulation response or substantial anal sphincter activation upon stimulation are spared.

\section{Outcome}

The outcome measures assessed in this study were onset of a new motor or sphincter deficit, mortality, wound infections, CSF leakages, and reoperations during the first 3 postoperative months. Motor deficits were detected through clinical examination postoperatively or subjectively reported by the parents or, if possible, the patient. Sphincter function was assessed through the return of preoperative micturition after removal of the urethral catheter at 3 days postoperatively, without urinary retention or recurrent urinary infections; new persistent constipation and fecal soiling were excluded by discussion with the parents or, if possible, the patient. Importantly, all patients underwent inpatient rehabilitation for at least 3 weeks, allowing close monitoring of motor and sphincter function. A new motor deficit or sphincter deficit would suggest unintentional transection of the ventral or sphincteric roots.

\section{Statistical Analysis}

Descriptive statistics were used to summarize the study cohort. All variables were assessed for normality using the Kolmogorov-Smirnov test, supplemented with histograms. To test for differences between group means/ 
TABLE 1. Grading system for EMG response to an intraoperative 1-second $50-\mathrm{Hz}$ train of stimulation, according to different authors

\begin{tabular}{|c|c|}
\hline Grade & EMG Response to Stimulation \\
\hline \multicolumn{2}{|l|}{ Fasano et al. ${ }^{6}$} \\
\hline Normal & One potential after the first stimulus only \\
\hline Abnormal & One potential after each stimulus, interferential record, other types of records, afterdischarge (variable) \\
\hline \multicolumn{2}{|c|}{ Phillips and Park 25,27} \\
\hline 0 & Unsustained or single discharge to a train of stimuli \\
\hline $1+$ & Sustained discharges from muscles innervated through the stimulated root in the ipsilateral lower limb \\
\hline $2+$ & Sustained discharges from the muscles innervated through the stimulated and immediately adjacent roots \\
\hline $3+$ & Sustained discharges from the muscles innervated through the stimulated root and roots distant from the stimulated one \\
\hline $4+$ & $\begin{array}{l}\text { Sustained discharges from muscles contralateral to those innervated through the stimulated root (irrespective of the pres- } \\
\text { ence of sustained discharges from the muscles ipsilateral to those innervated through the stimulated root) }\end{array}$ \\
\hline \multicolumn{2}{|l|}{ Mittal et al. ${ }^{20}$} \\
\hline 0 & Unsustained CMAP in any muscle \\
\hline $1+$ & Sustained CMAP from muscles innervated by the segmental level of the stimulated dorsal rootlet \\
\hline $2+$ & Same as grade $1+$ with CMAP in muscles innervated by an adjacent segmental level \\
\hline $3+$ & Same as grade 2+ with CMAP in muscles innervated by multiple ipsilateral segmental levels \\
\hline $4+$ & Same as grade $3+$ with motor response in the contralateral leg or upper extremity \\
\hline \multicolumn{2}{|l|}{ Hays et al. ${ }^{13}$} \\
\hline Normal & Target muscle responds with a single motor response, or with multiple responses and a decremental amplitude pattern \\
\hline Abnormal & $\begin{array}{l}\text { Motor response in target muscle with incremental amplitude pattern, motor response in nontargeted muscles; sustained } \\
\text { response persisting after the stimulus event with or without clonus pattern }\end{array}$ \\
\hline
\end{tabular}

CMAP = compound muscle action potential.

medians, we used the paired Student t-test, Friedman test with Dunn's multiple comparison, Wilcoxon matchedpairs signed-rank test, Mann-Whitney U-test, and Kruskal-Wallis test, as indicated. For correlation analysis, we calculated Spearman's rank correlation coefficient. All statistical analyses were conducted using SPSS (version 23.0, IBM Corp.). Statistical significance was defined as $\alpha$ $\leq 0.05$, and Bonferroni-corrected when applicable.

\section{Results \\ Demographics}

A total of 145 patients underwent SDR (93 boys, 64\%), with a mean age of 6 years and 7 months \pm 2 years and 3 months (range 2 years and 9 months to 14 years and 10 months) at surgery. Preoperative functional status was rated as GMFCS level II in 34 (23\%), GMFCS level III in 81 (56\%), and GMFCS level IV in 30 patients (21\%).

\section{Number of Rootlets}

Across the cohort, a total of 6320 rootlets were stimulated, with a median of 43 rootlets per patient (range 3066 rootlets). Consistent with the relative thickness of the roots, the L2 and L3 root were usually split into 3 rootlets each, while L4 was most commonly split in 4, L5 in 4 or 5 , and $\mathrm{S} 1$ in 5 (Table 2).

\section{Direct Stimulation Threshold}

The distribution across patients of the median direct stimulation threshold for the different rootlets is shown in Fig. 2A. The stimulation threshold of the dorsal rootlets was never below $0.2 \mathrm{~mA}$. The median stimulation threshold was lower when stimulating sacral versus lumbar roots ( $\mathrm{p}<0.001$; Friedman with Dunn's multiple comparison post hoc tests; Fig. 2A). The overall individual median threshold for the right-sided rootlets was slightly higher than for the left-sided ones (5.1 vs $4.3 \mathrm{~mA}, \mathrm{p}=0.023$; Wilcoxon matched-pairs signed-rank test), with the rootlets of L3 and S1 particularly accounting for this difference (Supplementary Table 1). There was a high individual correlation between abnormal response rate on both sides (Spearman $\mathrm{r}=0.58,95 \%$ confidence interval $[\mathrm{CI}] 0.45-0.68$, $\mathrm{p}<$ 0.0001; Supplementary Fig. 1).

There was no association between median overall stimulation threshold and age (Spearman $\mathrm{r}=0.06,95 \%$ CI -0.10 to 0.23 , p $=0.43$; Fig. $2 \mathrm{~B}$ ), and no difference between median overall stimulation thresholds when stratified by sex ( $\mathrm{p}=0.22$, Mann-Whitney U-test; Fig. 2C) or GMFCS level ( $\mathrm{p}=0.98$, Kruskal-Wallis test; Fig. 2D).

\section{Response to Stimulation}

The large majority $(5474 / 6320,87 \%)$ of rootlets responded to direct electrical stimulation with abnormal (grade $3+$ or $4+$ ) responses. When assessing the relative distribution of the responses per root, $\mathrm{S} 2$ rootlets displayed a higher abnormal response rate than any other $(p=0.01$, Friedman with Dunn's multiple comparison post hoc tests; Fig. 3A). Per root, overall stimulation responses were very similar when comparing both sides (Fig. 3A). Overall, there was a high individual correlation between abnormal response rates on both sides (Spearman $r=0.67,95 \%$ CI 0.57-0.75, p < 0.0001; Supplementary Fig. 1). 


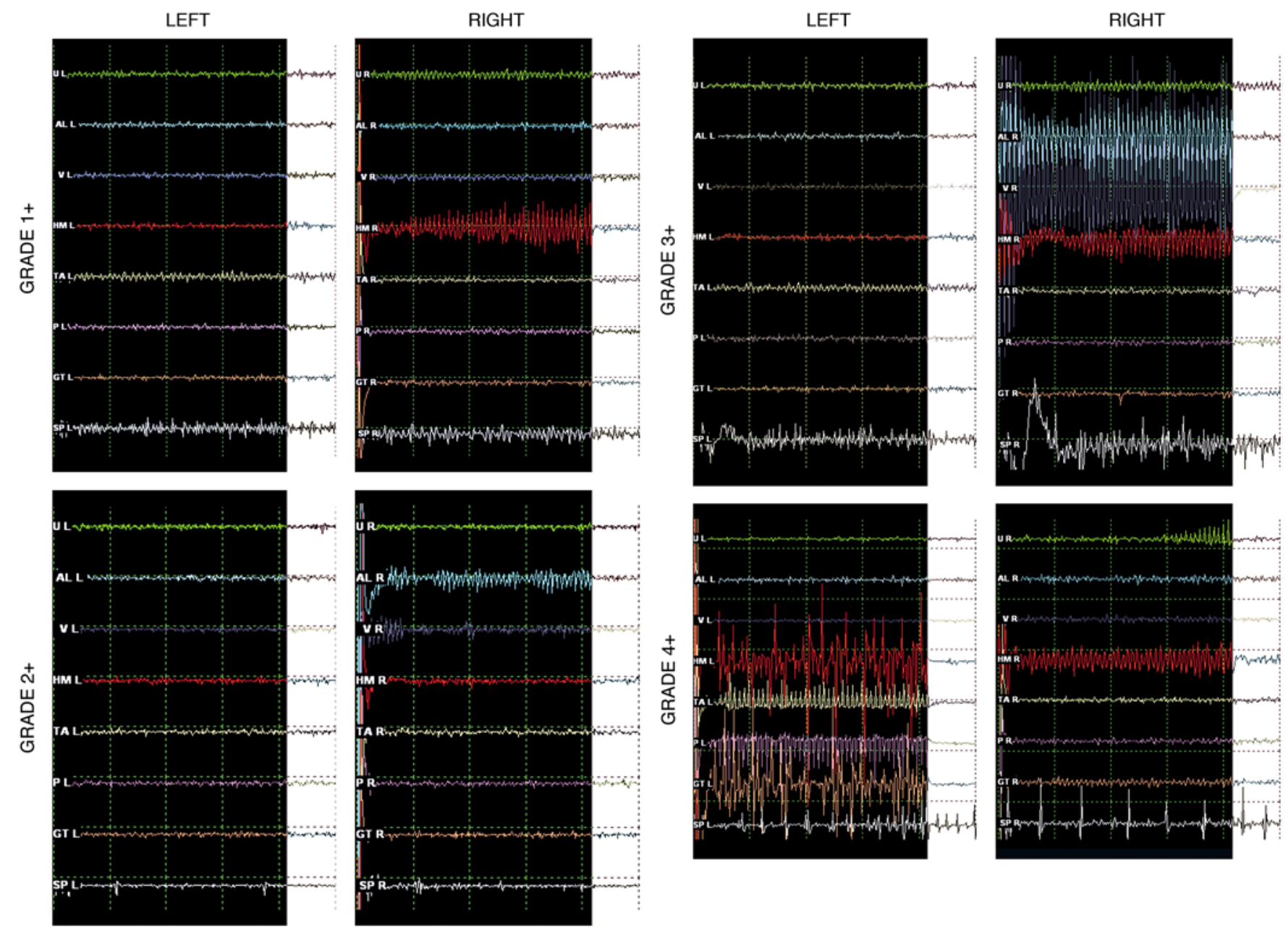

FIG. 1. Examples of grade $1+, 2+, 3+$, and $4+$ EMG responses to stimulation. Bilateral EMG traces illustrate the different Phillips and Park grades of response to electrical rootlet stimulation ${ }^{27}$ in a single patient (see Table 1 for a description of the respective grades). The black background marks the total duration (1 second) of electrical stimulation (0.2-msec square-wave pulses, $50 \mathrm{~Hz}$, stimulation threshold amplitude). One square represents $240 \mathrm{msec} \times 30 \mu \mathrm{V}$. Figure is available in color online only.

Among individual patients, the median abnormal response rate was $95 \%$, ranging from $36 \%$ to $100 \%$ (Fig. 3B). In 139/145 (96\%) of patients, the majority of rootlets displayed an abnormal response.

There was no correlation between the abnormal response rate and age (Spearman $\mathrm{r}=-0.02,95 \% \mathrm{CI}-0.18$ to $0.15, \mathrm{p}=0.86$; Fig. 3C). Furthermore, abnormal response rates did not differ when categorized by sex $(\mathrm{p}=$ 0.50 , Mann-Whitney U-test; Fig. 3D) or by preoperative GMFCS level ( $\mathrm{p}=0.80$, Kruskal-Wallis test; Fig. 3E).

\section{Transection Ratio}

Across all roots from L2 to S2, 61\% of the assessed rootlets were cut. The median transection ratio per patient was $60 \%$, ranging from $50 \%$ to $67 \%$ (Table 3 ).

\section{Outcome}

We have not observed any mortality, reoperations, wound infections, or CSF leakage in this series. None of the children experienced new motor or sphincter deficits, and in all children the indwelling urinary catheter was removed successfully without recurring urinary infections.

\section{Discussion}

In this series of 145 consecutive patients who under-

TABLE 2. Individual median number and range of rootlets stimulated

\begin{tabular}{ccc}
\hline Level & Right & Left \\
\hline L2 & $3(3-7)$ & $3(2-7)$ \\
\hline L3 & $3(2-8)$ & $3(3-11)$ \\
\hline L4 & $4(2-6)$ & $4(2-7)$ \\
\hline L5 & $5(3-8)$ & $4(2-7)$ \\
\hline S1 & $5(2-11)$ & $5(2-13)$ \\
\hline S2 & $3(2-6)$ & $3(1-6)$ \\
\hline Total & $22(15-34)$ & $21(15-32)$ \\
\hline
\end{tabular}



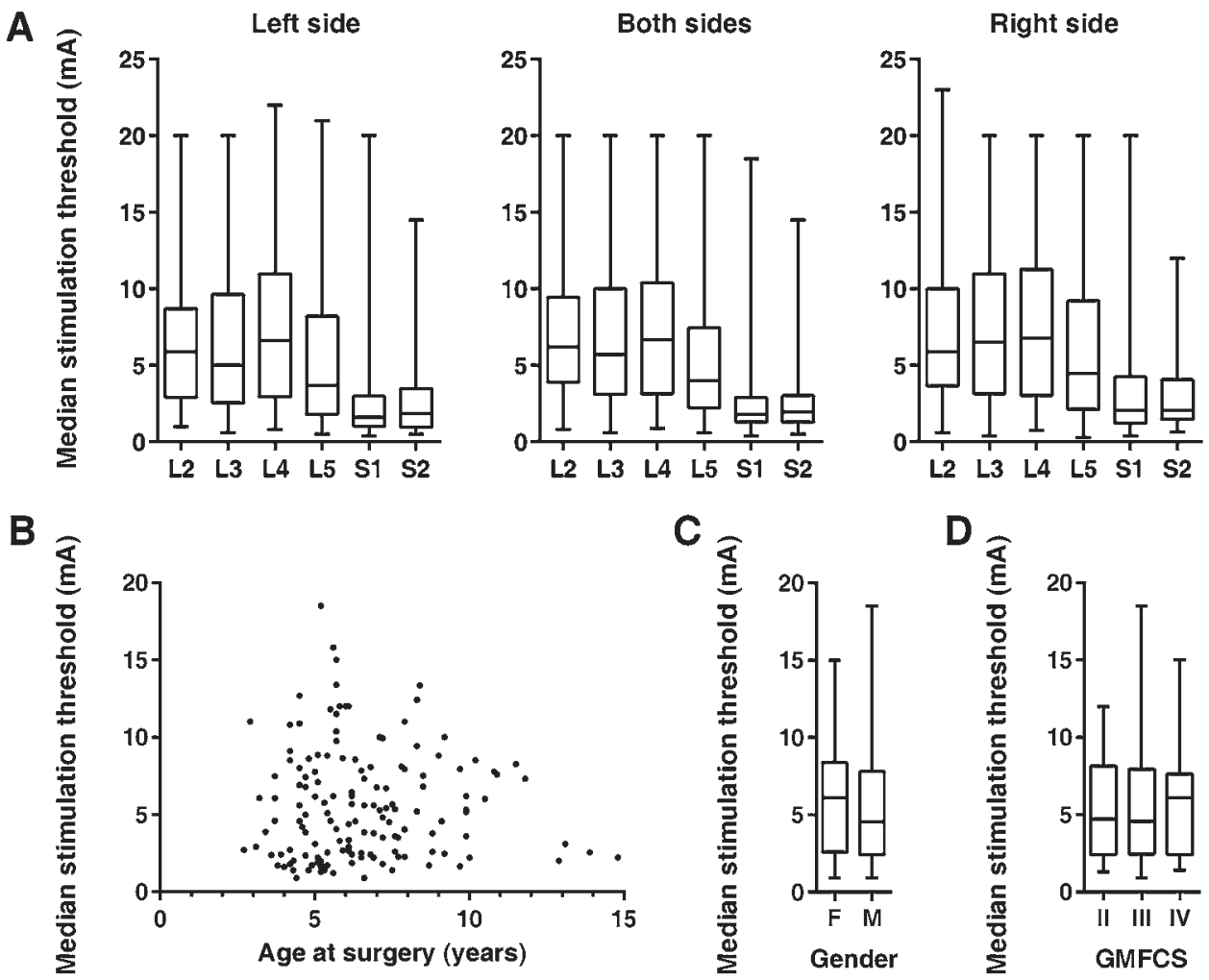

FIG. 2. Stimulation threshold. A: Distribution of the median stimulation threshold across patients, analyzed per root and per side. Error bars indicate range, while boxplots indicate 25th and 75th centiles, and median. B: Scatterplot demonstrating that there was no significant correlation between individual overall median stimulation threshold and age at surgery. Every dot represents a single patient. C and D: When stratifying patients by sex (gender) or GMFCS level, overall median stimulation thresholds did not differ significantly. Error bars indicate range, while boxplots indicate 25th and 75th centiles, and median.

went SDR via a single-level approach, we have used electrophysiology for three different purposes. First, it allows electrophysiological confirmation of the dorsal nature of a root. In addition to the response of free-running EMG to root manipulation, which is clear when the root is ventral but absent or minimal when the root is dorsal, the stimulation threshold appears to be a reliable marker. We were able to induce a clear EMG response as well as clinical response upon 0.05-0.1-mA stimulation of the ventral roots, whereas the stimulation threshold for dorsal roots and rootlets in this series was typically $>0.5 \mathrm{~mA}$ and never $<0.2 \mathrm{~mA}$. It is unlikely that we may have transected any ventral roots in our series, as we have not observed any new motor deficits postoperatively. It is also unlikely that we may have missed any dorsal roots, given the substantial and symmetrical improvement observed, as described previously. ${ }^{40}$

Second, electrophysiology can be used to confirm the level of the nerve root. Without performing a multilevel laminectomy, it is most likely impossible to prove unambiguously that a root level as identified electrophysiologically corresponds to its anatomical level. Hence, we have no proof that the electrophysiological root level identification is correct, although we have, in all patients in our cohort, identified anatomically separate roots, which, in lateromedial order, predominantly activated different muscles corresponding to the sequential craniocaudal roots.
Third, the electrophysiological response of every individual rootlet to direct electrical stimulation can be used as guidance when deciding which rootlets need to be spared or severed, aiming to maximize spasticity reduction and minimize the risk of incontinence. Without a study comparing the motor and sphincter outcome after SDR with and without intraoperative electrophysiology, it will remain an open question whether intraoperative electrophysiology truly provides a benefit. As we are unaware of any group who has conducted or is conducting such a study, we can only describe the functional outcome ${ }^{40}$ and the lack of new motor or sphincter deficits in this large series. This series also provides a benchmark to allow comparison with results of groups who do not use intraoperative electrophysiology.

Our data suggest that the threshold to electrical stimulation and the observed responses to tetanic stimulation are stable between patients, in this cohort with large variation in age, sex, and GMFCS level, as well as within individual patients, when comparing both sides. As we always begin with the right side, the left-sided values were obtained approximately 30-45 minutes later than the right-sided ones. This fixed order implicates a difference in length of anesthesia and surgical exposure, amount of CSF loss, and degree of manipulation and deafferentation by sectioning dorsal rootlets. Although the differences in threshold values between both sides were statistically significant, the 
A

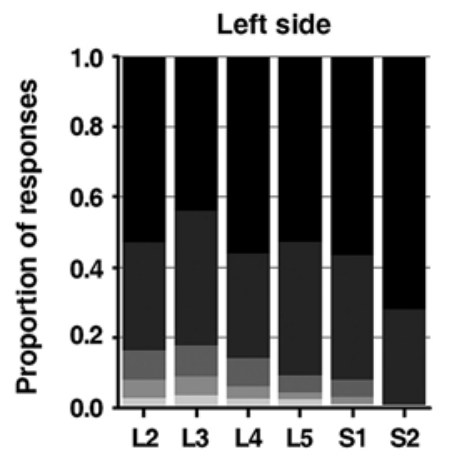

Both sides

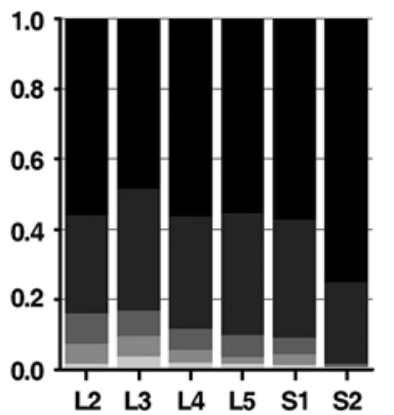

Right side

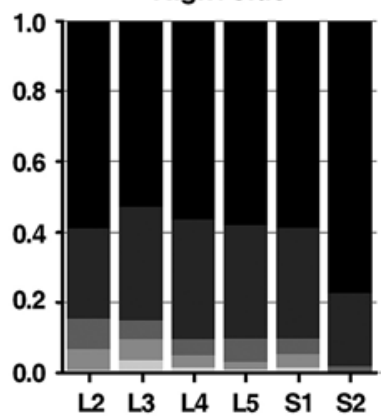

grade $3+$ grade $4+$

B

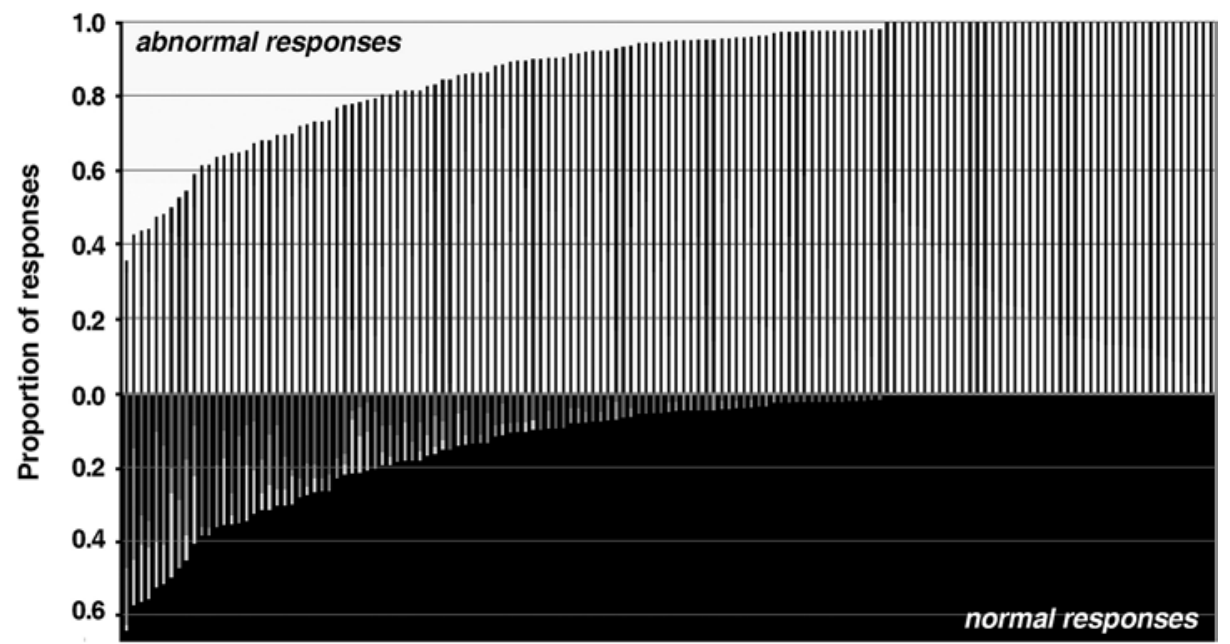

C

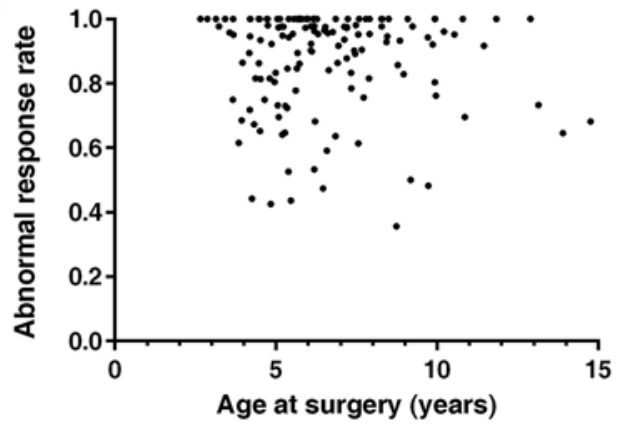

D

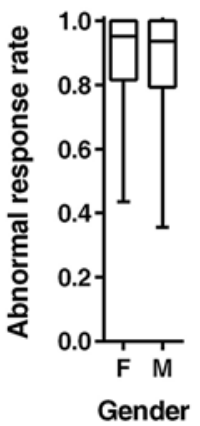

E

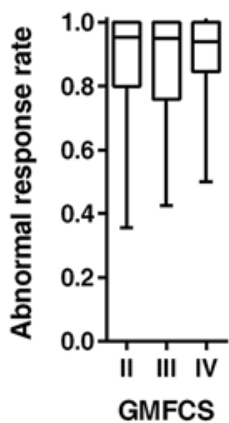

FIG. 3. Stimulation response. A: Relative proportion of the various stimulation response grades, analyzed per root and per side. B: For every individual patient (vertical bar), the relative distribution of the overall stimulation response grades is color-coded. The proportion of abnormal (grade $3+$ and $4+$ ) and normal (grade $0,1+$, and $2+$ ) responses is shown above and below the horizontal axis, respectively. C: There is no significant correlation between individual overall abnormal response rate and age at surgery. Every dot represents a single patient. D and E: When stratifying patients by sex (gender) or GMFCS level, overall abnormal stimulation response rate did not differ significantly. Error bars indicate range, while boxplots indicate 25 th and 75 th centiles, and median.

overall absolute value differed only by a median of $16 \%$ and there was a strong correlation between both sides, underlying the robustness of our method for threshold determination.

The stimulation threshold for the tested sacral roots was consistently lower than that for the lumbar roots. Whether this can be attributed to true anatomical differences or to the order of sectioning from L2 downwards cannot be determined from our data.
Similarly, the response to stimulation appeared to be relatively stable between patients, and when comparing right- and left-sided roots within single patients. Although we determined the stimulation threshold and response only once, our data suggests limited inter- and intrasubject variability. This result is in conflict with those from two studies that reported substantial variability upon retesting the stimulation threshold and response in small cohorts (n $=6$ and $n=8) .{ }^{42,43}$ However, Mittal et al., who repeatedly 
TABLE 3. Proportion of rootlets transected

\begin{tabular}{|c|c|c|c|}
\hline Level & Right & Left & Combined \\
\hline \multicolumn{4}{|l|}{ L2 } \\
\hline Overall proportion (\%) & $329 / 519(63)$ & $318 / 500(64)$ & $647 / 1019(63)$ \\
\hline Individual median (\%) & $2 / 3(67)$ & $2 / 3(67)$ & $4 / 6(67)$ \\
\hline Individual range & $33 \%-75 \%$ & $25 \%-75 \%$ & $43 \%-71 \%$ \\
\hline \multicolumn{4}{|l|}{ L3 } \\
\hline Overall proportion (\%) & $335 / 535(63)$ & $329 / 528(62)$ & $664 / 1063(62)$ \\
\hline Individual median (\%) & $2 / 3(67)$ & $2 / 3(67)$ & $4 / 6(67)$ \\
\hline Individual range & $33 \%-75 \%$ & $33 \%-75 \%$ & $46 \%-71 \%$ \\
\hline \multicolumn{4}{|l|}{ L4 } \\
\hline Overall proportion (\%) & $319 / 562(57)$ & $319 / 554(58)$ & $638 / 1116(57)$ \\
\hline Individual median (\%) & $2 / 4(50)$ & $2 / 4(50)$ & $4 / 8(50)$ \\
\hline Individual range & $40 \%-75 \%$ & $40 \%-67 \%$ & $44 \%-71 \%$ \\
\hline \multicolumn{4}{|l|}{ L5 } \\
\hline Overall proportion (\%) & $392 / 646$ (61) & $378 / 615(61)$ & $770 / 1261$ (61) \\
\hline Individual median (\%) & $3 / 5(60)$ & $3 / 4(75)$ & $4 / 7(57)$ \\
\hline Individual range & $40 \%-75 \%$ & $40 \%-75 \%$ & $44 \%-75 \%$ \\
\hline \multicolumn{4}{|l|}{ S1 } \\
\hline Overall proportion (\%) & 482/794 (61) & $491 / 792(62)$ & $973 / 1586(61)$ \\
\hline Individual median (\%) & $3 / 5(60)$ & $3 / 5(60)$ & $6 / 10(60)$ \\
\hline Individual range & $40 \%-75 \%$ & $33 \%-80 \%$ & $45 \%-80 \%$ \\
\hline \multicolumn{4}{|l|}{ S2 } \\
\hline Overall proportion (\%) & $72 / 148(49)$ & $62 / 127(49)$ & $134 / 275(49)$ \\
\hline Individual median (\%) & $2 / 3(67)$ & $1 / 3(33)$ & $2 / 5(40)$ \\
\hline Individual range & $0 \%-67 \%$ & $0 \%-67 \%$ & $25 \%-67 \%$ \\
\hline \multicolumn{4}{|l|}{ Total } \\
\hline Overall proportion (\%) & $1929 / 3204(60)$ & $1897 / 3116(61)$ & $3826 / 6320(61)$ \\
\hline Individual median (\%) & $13 / 22(59)$ & $13 / 21(62)$ & $26 / 43(60)$ \\
\hline Individual range & $50 \%-67 \%$ & $50 \%-69 \%$ & $50 \%-67 \%$ \\
\hline
\end{tabular}

After testing and transecting or sparing all rootlets between $\mathrm{L} 2$ and S2, $50 \%$ of the L1 root is arbitrarily transected.

stimulated rootlets in a large series $(n=77)$, also confirmed a high degree of consistency, with $93 \%$ of responses not differing more than one grade upon retesting. This was especially the case in rootlets with a 4+ response grade, in which $83 \%$ of rootlets displayed a $4+$ response again upon retesting. ${ }^{20}$ Furthermore, in this study, both stimulation threshold and response were unrelated to age, sex, or preoperative GMFCS level. The latter finding has been described previously in a series of 93 children with CP. ${ }^{13}$

Although there are currently no randomized studies comparing multilevel laminectomy/laminoplasty versus single-level laminectomy/laminoplasty for SDR, it may be that the single-level approach may result in less postoperative pain, a lower degree of long-term spinal instability, faster recovery, and shortened hospital stay. One study from Vancouver, comparing single-level laminectomy (n = 9) to historic-matched multilevel laminectomy SDR patients $(\mathrm{n}=18)$, described a shorter hospital stay (3.4 vs 5.2 days), but found no difference in postoperative pain or delay until mobilization..$^{22}$ We feel that the possible disadvantages of a single-level approach, including its limited exposure and resulting difficulties in determining the dorsal nature and the level of the visualized roots, can be largely overcome with intraoperative electrophysiology. By applying this method, we have not observed any worsening of continence in this series of 145 patients.

Many authors have challenged the validity of the currently used electrophysiological criteria, and even the necessity for electrophysiology to guarantee a good outcome with minimal risk. ${ }^{28,35}$ The arguments against the usefulness of electrophysiology are: 1) the high variability in monitoring technique and standards (Table 1), none of which is supported by good scientific evidence (most criteria being extrapolated from cat experiments $\left.{ }^{5}\right){ }^{16,34} 2$ ) the variability in segmental innervation of the lower extremity muscles; ${ }^{20} 3$ ) the possibility of co-stimulation of the ventral rootlets with high stimulation intensities; ${ }^{20} 4$ ) the refractoriness of roots to repeated stimulation; ${ }^{20} 5$ ) the absence of data from healthy controls; 6) the lack of association between the observed responses to stimulation and the degree of spasticity: ${ }^{13}$ 7) the existence of abnormal responses in children without spasticity; ${ }^{36,39} 8$ ) the variable circumstances during the procedure, including the quantity of CSF, level of anesthesia, positioning of stimulating 
electrodes, and the surgical manipulation to divide, handle, and suspend the rootlets; ${ }^{17,43}$ 9) the limited additional value of electrophysiology in selectively cutting abnormal roots when applied to a theoretical model ${ }^{28}$ and 10) the good short-term results reported in small cohorts undergoing SDR without electrophysiological guidance. ${ }^{32,38}$

Nonetheless, the majority of centers continue to use it. ${ }^{34}$ In favor of electrophysiological guidance for SDR is that our study and others ${ }^{20}$ show that the stimulation responses appear robust, and that one study found an association between stimulation response and histopathological characteristics of the rootlets, with axonal degeneration and dysmyelination apparent only in rootlets with an abnormal response to stimulation. ${ }^{?}$

We have learned three lessons over time. First, we have noticed that cutting approximately half of the sensory fibers of L1 improves hip spasticity as compared to when the rhizotomy is limited to L2 and below. Similarly, S2 rhizotomy appears to reduce ankle spasticity. Third, it is essential that anesthesia is kept constant throughout the procedure as even slight changes can alter stimulation thresholds.

This work represents the largest published body of intraoperative neurophysiological data in patients undergoing SDR. However, this study has several shortcomings. First, the presented values represent single measurements and we have not determined the degree of variability upon retesting. Second, this is a single-surgeon series, and the rating was performed by 1 of 3 electrophysiologists. There may exist a high degree of user dependency and we did not determine the interobserver variability. Third, this is a purely descriptive study and we can only hypothesize about the underlying factors for the observed differences between patients, and level and laterality of roots.

Fourth, the reported outcome is limited to new motor or sphincter deficits, as this is directly relevant to this neurophysiological study. We cannot exclude the possibility, however, that precontinent children who underwent SDR may have developed continence (earlier) if they had not undergone SDR. Fifth, we did not report on functional or quality of life outcome, as this is beyond the scope of this work. Nevertheless, these outcome measures have been published for a large subset of the cohort included in this study, as part of a multicenter outcome study in GMFCS level II and III children. ${ }^{40}$ Lastly, this study cannot determine whether there is a true benefit of using electrophysiology in the outcome and complication rate.

\section{Conclusions}

This study, describing the purpose, technique, and stimulation thresholds and responses in a large cohort of pediatric patients undergoing SDR, illustrates the potential value of intraoperative electrophysiology. Our results indicate that electrophysiology can reliably confirm the dorsal nature and level of roots, and can be used to guide which rootlets to transect. Our method appears robust, as illustrated by the stimulation threshold and response grade being stable when comparing both sides within single patients, and between patients, irrespective of age, sex, and functional states. Further work is needed to determine whether the use of electrophysiology during SDR procedures maximizes the long-term benefit and/or minimizes complications.

\section{Acknowledgments}

P.D.V. is supported by the 2016 Research Grant of the European Society for Stereotactic and Functional Neurosurgery and by the Helaers Foundation. K.A. runs an SDR assessment clinic and performs SDR procedures, both in the NHS and in private practice.

\section{References}

1. Abbe R: Resection of the posterior roots of spinal nerves to relieve pain, pain reflex, athetosis and spastic paralysis-Dana's operation. Med Rec 79:377-381, 1911

2. Aquilina K, Graham D, Wimalasundera N: Selective dorsal rhizotomy: an old treatment re-emerging. Arch Dis Child 100:798-802, 2015

3. Cahan LD, Kundi MS, McPherson D, Starr A, Peacock W: Electrophysiologic studies in selective dorsal rhizotomy for spasticity in children with cerebral palsy. Appl Neurophysiol 50:459-462, 1987

4. Chicoine MR, Park TS, Kaufman BA: Selective dorsal rhizotomy and rates of orthopedic surgery in children with spastic cerebral palsy. J Neurosurg 86:34-39, 1997

5. Decandia M, Provini L, Taborikova H: Mechanisms of the reflex discharge depression in the spinal motoneurone during repetitive orthodromic stimulation. Brain Res 4:284-291, 1967

6. Fasano VA, Barolat-Romana G, Zeme S, Squazzi A: Electrophysiological assessment of spinal circuits in spasticity by direct dorsal root stimulation. Neurosurgery 4:146-151, 1979

7. Fasano VA, Broggi G, Barolat-Romana G, Sguazzi A: Surgical treatment of spasticity in cerebral palsy. Childs Brain 4:289-305, 1978

8. Foerster O: On the indications and results of the excision of posterior spinal nerve roots in men. Surg Gynecol Obstet 16:463-474, 1913

9. Fukuhara T, Nakatsu D, Namba Y, Yamadori I: Histological evidence of intraoperative monitoring efficacy in selective dorsal rhizotomy. Childs Nerv Syst 27:1453-1458, 2011

10. Funk JF, Haberl H: Monosegmental laminoplasty for selective dorsal rhizotomy-operative technique and influence on the development of scoliosis in ambulatory children with cerebral palsy. Childs Nerv Syst 32:819-825, 2016

11. Golan JD, Hall JA, O'Gorman G, Poulin C, Benaroch TE, Cantin MA, et al: Spinal deformities following selective dorsal rhizotomy. J Neurosurg 106 (6 Suppl):441-449, 2007

12. Gros C, Ouaknine G, Vlahovitch B, Frèrebeau P: [Selective posterior radicotomy in the neurosurgical treatment of pyramidal hypertension.] Neurochirurgie 13:505-518, 1967 (French)

13. Hays RM, McLaughlin JF, Bjornson KF, Stephens K, Roberts TS, Price R: Electrophysiological monitoring during selective dorsal rhizotomy, and spasticity and GMFM performance. Dev Med Child Neurol 40:233-238, 1998

14. Hurvitz EA, Marciniak CM, Daunter AK, Haapala HJ, Stibb SM, McCormick SF, et al: Functional outcomes of childhood dorsal rhizotomy in adults and adolescents with cerebral palsy. J Neurosurg Pediatr 11:380-388, 2013

15. Lang FF, Deletis V, Cohen HW, Velasquez L, Abbott R: Inclusion of the $\mathrm{S} 2$ dorsal rootlets in functional posterior rhizotomy for spasticity in children with cerebral palsy. Neurosurgery 34:847-853, 1994

16. Logigian EL, Shefner JM, Goumnerova L, Scott RM, Soriano SG, Madsen J: The critical importance of stimulus intensity in intraoperative monitoring for partial dorsal rhizotomy. Muscle Nerve 19:415-422, 1996 
17. Logigian EL, Soriano SG, Herrmann DN, Madsen JR: Gentle dorsal root retraction and dissection can cause areflexia: implications for intraoperative monitoring during "selective" partial dorsal rhizotomy. Muscle Nerve 24:1352-1358, 2001

18. McLaughlin J, Bjornson K, Temkin N, Steinbok P, Wright V, Reiner A, et al: Selective dorsal rhizotomy: meta-analysis of three randomized controlled trials. Dev Med Child Neurol 44:17-25, 2002

19. McLaughlin JF, Bjornson KF, Astley SJ, Graubert C, Hays RM, Roberts TS, et al: Selective dorsal rhizotomy: efficacy and safety in an investigator-masked randomized clinical trial. Dev Med Child Neurol 40:220-232, 1998

20. Mittal S, Farmer JP, Poulin C, Silver K: Reliability of intraoperative electrophysiological monitoring in selective posterior rhizotomy. J Neurosurg 95:67-75, 2001

21. O’Brien DF, Park TS, Puglisi JA, Collins DR, Leuthardt EC: Effect of selective dorsal rhizotomy on need for orthopedic surgery for spastic quadriplegic cerebral palsy: long-term outcome analysis in relation to age. J Neurosurg 101 (1 Suppl):59-63, 2004

22. Ou C, Kent S, Miller S, Steinbok P: Selective dorsal rhizotomy in children: comparison of outcomes after single-level versus multi-level laminectomy technique. Can J Neurosci Nurs 32:17-24, 2010

23. Palisano R, Rosenbaum P, Walter S, Russell D, Wood E, Galuppi B: Development and reliability of a system to classify gross motor function in children with cerebral palsy. Dev Med Child Neurol 39:214-223, 1997

24. Park TS, Gaffney PE, Kaufman BA, Molleston MC: Selective lumbosacral dorsal rhizotomy immediately caudal to the conus medullaris for cerebral palsy spasticity. Neurosurgery 33:929-934, 1993

25. Park TS, Johnston JM: Surgical techniques of selective dorsal rhizotomy for spastic cerebral palsy. Technical note. Neurosurg Focus 21(2):e7, 2006

26. Peacock WJ, Staudt LA: Spasticity in cerebral palsy and the selective posterior rhizotomy procedure. J Child Neurol 5:179-185, 1990

27. Phillips LH, Park TS. Electrophysiologic studies of selective posterior rhizotomy patients, in Park TS, Phillips LH II, Peacock WJ (eds): Management of Spasticity in Cerebral Palsy and Spinal Cord Injury. Neurosurgery: State of the Art Reviews, Vol 4. Philadelphia: Hanley \& Belfus, 1989, pp 459-469

28. Pollack MA: Limited benefit of electrophysiological studies during dorsal rhizotomy. Muscle Nerve 17:553-555, 1994

29. Privat JM, Benezech J, Frerebeau P, Gros C: Sectorial posterior rhizotomy, a new technique of surgical treatment for spasticity. Acta Neurochir (Wien) 35:181-195, 1976

30. Ravindra VM, Christensen MT, Onwuzulike K, Smith JT, Halvorson K, Brockmeyer DL, et al: Risk factors for progressive neuromuscular scoliosis requiring posterior spinal fusion after selective dorsal rhizotomy. J Neurosurg Pediatr 20:456-463, 2017

31. Riegle EV, Gunter JB, Lagueruela RG, Park TS, Owen J: Anesthesia for selective dorsal rhizotomy in children. J Neurosurg Anesthesiol 4:182-187, 1992

32. Sacco DJ, Tylkowski CM, Warf BC: Nonselective partial dorsal rhizotomy: a clinical experience with 1-year follow-up. Pediatr Neurosurg 32:114-118, 2000

33. Steinbok P, Hicdonmez T, Sawatzky B, Beauchamp R, Wickenheiser D: Spinal deformities after selective dorsal rhizotomy for spastic cerebral palsy. J Neurosurg 102 (4 Suppl):363-373, 2005

34. Steinbok P, Kestle JR: Variation between centers in electrophysiologic techniques used in lumbosacral selective dorsal rhizotomy for spastic cerebral palsy. Pediatr Neurosurg 25:233-239, 1996

35. Steinbok P, Keyes R, Langill L, Cochrane DD: The validity of electrophysiological criteria used in selective functional posterior rhizotomy for treatment of spastic cerebral palsy. $\mathbf{J}$ Neurosurg 81:354-361, 1994

36. Steinbok P, Langill L, Cochrane DD, Keyes R: Observations on electrical stimulation of lumbosacral nerve roots in children with and without lower limb spasticity. Childs Nerv Syst 8:376-382, 1992

37. Steinbok P, Reiner AM, Beauchamp R, Armstrong RW, Cochrane DD, Kestle J: A randomized clinical trial to compare selective posterior rhizotomy plus physiotherapy with physiotherapy alone in children with spastic diplegic cerebral palsy. Dev Med Child Neurol 39:178-184, 1997

38. Steinbok P, Tidemann AJ, Miller S, Mortenson P, BowenRoberts T: Electrophysiologically guided versus non-electrophysiologically guided selective dorsal rhizotomy for spastic cerebral palsy: a comparison of outcomes. Childs Nerv Syst 25:1091-1096, 2009

39. Storrs BB, Nishida T: Use of the ' $H$ ' reflex recovery curve in selective posterior rhizotomy. Pediatr Neurosci 14:120-123, 1988

40. Summers J, Coker B, Eddy S, Elstad M, Bunce C, Bourmpaki E, et al: Selective dorsal rhizotomy in ambulant children with cerebral palsy: an observational cohort study. Lancet Child Adolesc Health 3:455-462, 2019

41. Turner RP: Neurophysiologic intraoperative monitoring during selective dorsal rhizotomy. J Clin Neurophysiol 26:8284,2009

42. Warf BC, Nelson KR: The electromyographic responses to dorsal rootlet stimulation during partial dorsal rhizotomy are inconsistent. Pediatr Neurosurg 25:13-19, 1996

43. Weiss IP, Schiff SJ: Reflex variability in selective dorsal rhizotomy. J Neurosurg 79:346-353, 1993

44. Wong AMK, Pei YC, Lui TN, Chen CL, Wang CM, Chung $\mathrm{CY}$ : Comparison between botulinum toxin type A injection and selective posterior rhizotomy in improving gait performance in children with cerebral palsy. J Neurosurg 102 (4 Suppl):385-389, 2005

45. Wright FV, Sheil EM, Drake JM, Wedge JH, Naumann S: Evaluation of selective dorsal rhizotomy for the reduction of spasticity in cerebral palsy: a randomized controlled trial. Dev Med Child Neurol 40:239-247, 1998

\section{Disclosures}

Dr. De Vloo reports receiving grants for travel and education from Medtronic, Boston Scientific, and St. Jude/Abbott.

\section{Author Contributions}

Conception and design: Aquilina, De Vloo, Huttunen. Acquisition of data: De Vloo, Huttunen, Forte, Jankovic, Lee. Analysis and interpretation of data: Aquilina, De Vloo. Drafting the article: De Vloo. Critically revising the article: Aquilina, Huttunen, Forte, Jankovic, Lee, Hair, Cawker, Chugh, Carr, Crowe, Pitt. Reviewed submitted version of manuscript: all authors. Approved the final version of the manuscript on behalf of all authors: Aquilina. Statistical analysis: De Vloo. Study supervision: Aquilina.

\section{Supplemental Information Online-Only Content}

Supplemental material is available with the online version of the article.

Supplementary Table 1 and Figs. 1 and 2. https://thejns.org/ doi/suppl/10.3171/2019.12.PEDS19372.

\section{Correspondence}

Kristian Aquilina: Great Ormond Street Hospital for Children NHS Trust, London, United Kingdom. kristian.aquilina@gosh. nhs.uk. 